\section{Visual evoked potentials at, above, and below two-flash thresholds*}

\author{
J. L. ANDREASSI, M. S. MAYZNER, S. DAVIDOVICS, and D. R. BEYDA \\ New York University, Bronx, N.Y. 10453
}

The present study is concerned with relating the effects of varying interstimulus interval (ISI) values on visually evoked potentials (VEPs) for pairs of light flashes, where both light flashes have equal luminance values. The results provide further evidence that ISI values and number of stimuli presented affect VEPs, even for equal luminance pairs of light flashes.

Over the past decade increasing use has been made of visual evoked potentials (VEPs) to study problems of visual information processing in man. Most recently, Riggs (1969) has provided a summary of this work. A persisting issue within this problem domain has been the effects of light flashes, separated by varying interstimulus interval (ISI) values, on VEPs, and a number of studies (e.g., Donchin, Wicke, \& Lindsley, 1963; Donchin \& Lindsley, 1965; Harter \& White, 1967) have examined this question.

The present study is concerned with examining the effects of paired light flashes on VEPs further, but in contrast to most of the previous work done in this field, both light flashes assume equal luminance values in the present experiment. Our specific objective, then, is to assess the effect of varying ISI values for paired light flashes on VEPs, where (1) the double flash is well below a two-flash threshold, such that only one light flash is ever reported, (2) the double flash is at threshold, such that either one or two flashes are equally likely to be reported, and ( 3 ) the double flash is well above threshold, such that two flashes are almost always reported.

$$
\text { SUBJECTS }
$$

The Ss were eight males, none of whom had visual defects other than myopia (corrected to 20/20).

\section{APPARATUS AND PROCEDURE}

The experiment can be described as having two distinct phases. In Phase 1 the two-flash threshold of the $S$ was established. This was done in the following manner: The $S$ was seated in a lit IAC chamber (Type 403A) $2 \mathrm{ft}$ away from a Grass photostimulator, which flashed through the window and screen to Ss' position, at eye level. (The room was lit because pilot experimentation showed that the flash intensity at the setting used was extremely fatiguing to a dark-adapted $\mathrm{S}$; in fact, a ground glass had to be

\footnotetext{
* This research was supported by the Physiological Psychology Program, Office of Naval Research, under ONR Contract No. N00014-67-A-0467-0009 and ONR Contract Authority No. NR 140-252 to the first two authors.
}

placed over the PS-2 to reduce flash intensity further.) The PS-2 was operated at intensity No. 1 (lowest) and delivered two consecutive flashes of 10 microsec duration. The first set of flashes were $15 \mathrm{msec}$ apart. The $S$ was asked to report either "one" or "two" to the E. This process was continued with increments of 3-msec time separation until the $\mathrm{S}$ said his first "two." Upon seeing his first "two," three more trials with increments of $1 \mathrm{msec}$ each were presented to the $S$, to assure a definite "two" at that millisecond time separation. The same procedure was followed starting with 140-msec separations, descending $3 \mathrm{msec}$, and recording the first "one." An average of six trials was found and used as the threshold value for the rest of the experiment.

In Phase 2, the EEG was recorded from a silver-coated cup electrode (Grass Type E5) placed at 02 (right occipital area), according to the
"Ten-Twenty" International System (Jasper, 1958). The EEG was amplified and written out on an Offner Type RM dynograph. Amplification was accomplished by a preamplifier gain setting of $2 \mathrm{mV} / \mathrm{cm}$ multiplied by a power amplifier setting of 0.02 . Calibration then showed that a $1-\mathrm{cm}$ pen deflection was equivalent to 40 microV of EEG amplitude. Offner ac coupler (Type 9806A) was used to condition the EEG signal with a high frequency setting of 2 and time constant of .03. The lead from 02 was referred to a silver Grass clip electrode on the left earlobe (Type E34S). S was grounded by means of an electrode-strap combination attached to the ventral surface of his left wrist. Electrode resistance was routinely checked before EEG was recorded.

EEG potentials were fed into a Mnemotron Computer of Average Transients (CAT 1000) to produce the averaged VEP. Samples of EEG activity of $500 \mathrm{msec}$ duration following each stimulus were summated and, upon termination of a given trial, written out on an Hewlett-Packard 7004A X-Y plotter.

The paired stimuli were manually flashed by $\mathrm{E}$ at 1- to 4 -sec intervals to help insure attention to the task by avoiding "automatic" response on the part of S. S was instructed to respond with "one" or "two" after each stimulus, and $E$ recorded the response. Each trial consisted of $100 \mathrm{~s}$ such stimuli.

The experiment consisted of the four following conditions: (A) The

Mean Amplitudes $(\mu \mathrm{v})$ for Major Positive Components of VEP Under Conditions of Double (A, B, C) and Single (D) Light Flashes

\begin{tabular}{|c|c|c|c|c|c|}
\hline \multirow[b]{2}{*}{$s$} & & \multicolumn{4}{|c|}{ Condition } \\
\hline & & $\mathrm{A}$ & $\mathrm{B}$ & $\mathrm{C}$ & D \\
\hline 1 (D.B.) & $\begin{array}{l}\text { P1 } \\
\text { P2 } \\
\text { P3 }\end{array}$ & $\begin{array}{c}5.34 \\
14.64 \\
-\end{array}$ & $\begin{array}{r}6.65 \\
16.71 \\
7.42\end{array}$ & $\begin{array}{r}5.89 \\
11.74 \\
6.12\end{array}$ & $\begin{array}{r}5.21 \\
12.60 \\
-\end{array}$ \\
\hline 2 (J.A.) & $\begin{array}{l}\text { P1 } \\
\text { P2 } \\
\text { P3 }\end{array}$ & $\begin{array}{r}4.10 \\
28.07 \\
-\end{array}$ & $\begin{array}{r}4.21 \\
25.91 \\
-\end{array}$ & $\begin{array}{r}5.01 \\
22.93 \\
4.89\end{array}$ & $\begin{array}{r}4.82 \\
26.38 \\
-\end{array}$ \\
\hline 3 (J.K.) & $\begin{array}{l}\text { P1 } \\
\text { P2 } \\
\text { P3 }\end{array}$ & $\begin{array}{c}7.38 \\
25.54 \\
-\end{array}$ & $\begin{array}{r}7.39 \\
21.89 \\
-\end{array}$ & $\begin{array}{r}9.34 \\
30.28 \\
5.85\end{array}$ & $\begin{array}{r}8.46 \\
24.76 \\
-\end{array}$ \\
\hline 4 (M.L.) & $\begin{array}{l}\text { P1 } \\
\text { P2 } \\
\text { P3 }\end{array}$ & $\begin{array}{r}8.13 \\
24.90 \\
7.76\end{array}$ & $\begin{array}{r}6.65 \\
23.09 \\
7.36\end{array}$ & $\begin{array}{r}8.06 \\
24.66 \\
7.82\end{array}$ & $\begin{array}{r}6.80 \\
23.65 \\
7.05\end{array}$ \\
\hline 5 (J.G.) & $\begin{array}{l}\text { P1 } \\
\text { P2 } \\
\text { P3 }\end{array}$ & $\begin{array}{r}5.99 \\
15.60 \\
-\end{array}$ & $\begin{array}{r}5.94 \\
13.91 \\
6.94\end{array}$ & $\begin{array}{r}6.83 \\
17.63 \\
6.96\end{array}$ & $\begin{array}{r}4.11 \\
15.05 \\
-\end{array}$ \\
\hline 6 (J.M.) & $\begin{array}{l}\text { P1 } \\
\text { P2 } \\
\text { P3 }\end{array}$ & $\begin{array}{c}7.61 \\
30.03 \\
-\end{array}$ & $\begin{array}{r}8.79 \\
35.08 \\
6.67\end{array}$ & $\begin{array}{r}7.82 \\
17.86 \\
9.02\end{array}$ & $\begin{array}{r}7.15 \\
30.52 \\
-\end{array}$ \\
\hline 7 (F.S.) & $\begin{array}{l}\text { P1 } \\
\text { P2 } \\
\text { P3 }\end{array}$ & $\begin{array}{l}2.43 \\
8.53 \\
7.06\end{array}$ & $\begin{array}{l}2.14 \\
5.24 \\
6.36\end{array}$ & $\begin{array}{l}2.93 \\
8.33 \\
7.91\end{array}$ & $\begin{array}{l}2.44 \\
7.47 \\
7.68\end{array}$ \\
\hline 8 (M.Le) & $\begin{array}{l}\text { P1 } \\
\text { P2 } \\
\text { P3 }\end{array}$ & $\begin{array}{r}6.43 \\
14.22 \\
16.45\end{array}$ & $\begin{array}{r}7.14 \\
15.49 \\
7.63\end{array}$ & $\begin{array}{r}7.06 \\
13.88 \\
6.65\end{array}$ & $\begin{array}{r}6.72 \\
18.18 \\
-\end{array}$ \\
\hline
\end{tabular}


Table 2

Mean Amplitude (in $\mu v$ ) of P2 Under Four Flash Conditions

\begin{tabular}{lrrrr}
\hline & \multicolumn{5}{c}{ Condition } \\
\cline { 2 - 5 } S & \multicolumn{1}{c}{ A } & \multicolumn{1}{c}{ B } & \multicolumn{1}{c}{ C } & \multicolumn{1}{c}{ D } \\
\hline 1 (D.B.) & 14.64 & 16.71 & 11.74 & 12.60 \\
2 (J.A.) & 28.07 & 25.91 & 22.93 & 26.36 \\
3 (J.K.) & 25.54 & 21.89 & 30.28 & 24.76 \\
4 (M.L.) & 24.90 & 23.09 & 24.66 & 23.65 \\
5 (J.G.) & 15.60 & 13.09 & 17.63 & 15.05 \\
6 (J.M.) & 30.03 & 35.08 & 17.86 & 30.52 \\
7 (F.S.) & $\mathbf{8 . 5 3}$ & 5.24 & 8.33 & 7.47 \\
8 (M.Le) & 14.22 & 15.49 & 13.88 & 18.18 \\
Mean & 20.90 & 19.61 & 18.40 & 19.80 \\
\hline
\end{tabular}

stimulus consisted of two consecutive flashes, $50 \mathrm{msec}$ below the S's threshold; (B) the stimulus presented was at threshold; (C) the stimulus consisted of two consecutive flashes, $50 \mathrm{msec}$ above the $S$ 's threshold; and (D) the stimulus consisted of a single flash.

The $\mathrm{S}$ was told to "fixate on the flashing light and try not to blink." During the conduct of a previous study (Andreassi, Mayzner, Beyda, \& Davidovics, 1970), we found that EOG potentials do not affect VEP recordings from 02 if $S$ does not blink regularly during stimulus presentation. Each condition included the 100 summations of EEG activity. The PS-2 was used to trigger the CAT on all trials. The four conditions were counterbalanced among the eight Ss by a Latin-square design.

Experimental data were collected over a period of 4 weeks. Six tracings of VEPs were obtained for each $S$ under each condition. Since each tracing was based on responses to 100 stimuli, each $S$ observed 2,400 presentations during the course of the experiment. A record of S's reports of "one" or "two" was made by E for each stimulus presentation. Threshold values for our Ss ranged from 55 to $86 \mathrm{msec}$. Since $15 \mathrm{msec}$ was the lowest ISI setting for the PS-2, this was used as the lower ISI value for three Ss with thresholds below $65 \mathrm{msec}$. Ss reported to the laboratory at the same time each week to keep diumal conditions as constant as possible over sessions.

RESULTS AND DISCUSSION

The mean amplitudes (microvolts) and iatencies (milliseconds) for each of the major positive components of the VEP were computed for each of the eight Ss. The latency data did not prove useful because of the differing interflash intervals among Ss. The P1 component was measured as the vertical distance between the trough of the first negative wave (N1) to the peak of the first positive component, P2 was measured as the vertical distance between $\mathrm{N} 2$ and the peak of the second positive component, and

Table 3

Percentage of Time $T u_{0}$ Flashes Were Reported Compared With Number and Overall Percentage of Times P3 Occurred (Six Traces for Each Condition)

\begin{tabular}{|c|c|c|c|c|c|c|c|c|}
\hline \multirow[b]{3}{*}{$\mathrm{S}$} & \multicolumn{8}{|c|}{ Condition } \\
\hline & \multicolumn{2}{|c|}{ A } & \multicolumn{2}{|c|}{ B } & \multicolumn{2}{|l|}{$\mathrm{C}$} & \multicolumn{2}{|c|}{$\mathrm{D}$} \\
\hline & $\begin{array}{c}\text { "Two" } \\
\text { Reported }\end{array}$ & P3 & $\begin{array}{c}\text { "Two" } \\
\text { Reported }\end{array}$ & P3 & $\begin{array}{c}\text { "Two" } \\
\text { Reported }\end{array}$ & P3 & $\begin{array}{c}\text { "Two" } \\
\text { Reported }\end{array}$ & P3 \\
\hline 1 (D.B.) & 0 & 0 & 58 & 6 & 100 & 5 & 0 & 0 \\
\hline 2 (J.A.) & 0 & 0 & 69 & 0 & 100 & 5 & 0 & 0 \\
\hline $3(J . K)$. & 0 & 0 & 49 & 0 & 100 & 6 & 0 & 0 \\
\hline 4 (M.L.) & 0 & 6 & 49 & 3 & 100 & 6 & 0 & 2 \\
\hline 5 (J.G.) & 0 & 0 & 45 & 4 & 100 & 6 & 0 & 0 \\
\hline 6 (J.M.) & 0 & 0 & 57 & 4 & 100 & 6 & 0 & 0 \\
\hline 7 (F.S.) & 0 & 4 & 52 & 5 & 100 & 6 & 0 & 4 \\
\hline 8 (M.Le) & 0 & 5 & 43 & 4 & 100 & 4 & 0 & 0 \\
\hline $\begin{array}{c}\text { Overall } \\
\text { Percentage }\end{array}$ & $0 \%$ & $31.2 \%$ & $52.6 \%$ & $55.4 \%$ & $100 \%$ & $91.6 \%$ & $0 \%$ & $13 \%$ \\
\hline
\end{tabular}

P3, when it occurred, was measured from N3 to the peak of the third positive component. Table 1 shows the mean amplitudes for $\mathrm{P} 1, \mathrm{P} 2$, and $\mathrm{P} 3$ under the four experimental conditions. The blank spaces in the table indicate that a particular component did not occur under that condition.

The eight Ss consistently produced a sizable $\mathrm{P} 2$ response, and the mean amplitude of this component was averaged for each $S$ under the four experimental conditions, as shown in Table 2. Each mean is the average of six tracings.

Condition A produced the largest P2, while Condition $C$ produced the smallest. These differences were

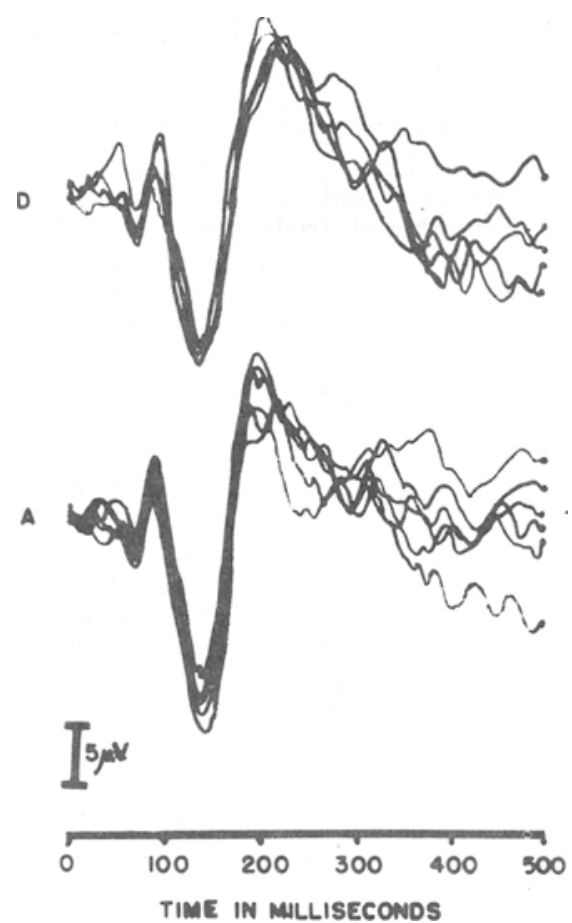

analyzed by t tests for correlated data (two-tailed) under all possible combinations; none were statistically significant $(\mathrm{p}>.05, \mathrm{df}=7)$

A more important result proved to be the number of waveform components under the four conditions. As an example, Fig. 1 shows the six VEPs superimposed, for one $\mathrm{S}$, under each condition.

The tracings show that the VEPs to Conditions $\mathrm{A}$ and $\mathrm{D}$ are very similar. For Condition B (threshold) an extra component appears, constituting an N3-P 3 component, while in Condition $\mathrm{C}$ a similar N3-P3 appears. Inspection shows that this $\mathrm{P} 3$ is flatter than $\mathrm{P} 1$ or $\mathrm{P} 2$ and of lower amplitude than P2.
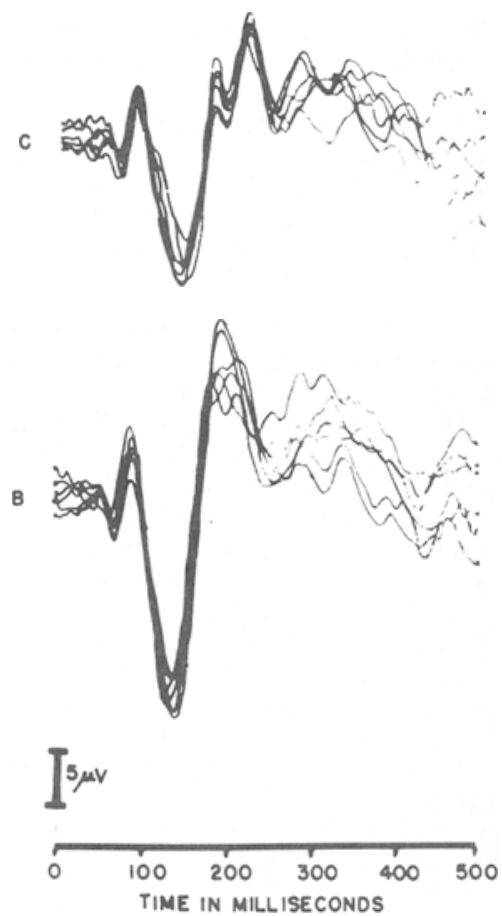

Fig. 1. VEPs of one S (J. M. ) to Conditions D (one flash), A (15-msec ISI, C (106-msec ISI, and B (56-msec ISI). Actual order of presentation. Negativity is downward. Each trace based on responses to 100 presentations. 
A more detailed analysis of the P3 response is shown in Table 3 . Also shown is ththe perceptual correlate of P3, i.e., the percentage of time two flashes were reported under each condition, compared with the number of times P3 was found in the VEP tracings for each $\mathrm{S}$.

The results in Table 3 indicate that the different conditions produced the desired effects, i.e., Condition A never produced a response of "two," while C always produced a response of "two" for all $\mathrm{Ss}$. Correlated $t$ tests (two-tailed) indicate that P3 was an important physiological correlate of the "two" response. The most interesting difference ( $\mathrm{A}$ vs $\mathrm{C}, \mathrm{t}=3.56$, $\mathrm{df}=7, \quad \mathrm{p}<.01)$ indicated that $\mathrm{P3}$ occurred a significantly greater number of times when two flashes were reported than when one flash was reported Also significant is the difference between Conditions $C$ vs $D$ $(\mathrm{t}=9.67, \quad \mathrm{df}=7, \quad \mathrm{p}<.01), \quad \mathrm{B}$ vs $\mathrm{D}$ $(t=3.12, d f=7, p<.02)$, and $B$ vs $C$ $(t=268, d f=7, p<.05)$. The other two comparisons, $A$ vs $B$ and $A$ vs $D$, did not yield significant differences.

The results suggest that $P 3$ represents some portion of an evoked response to the second flash. Since the $\mathrm{VEP}$ to a brief stimulus lasts longer than the duration of the stimulus, the VEPs overlap to greater extent with shorter ISIs. Thus, the number of positive components obtained in the VEPs is clearly related to the number of flashes reported by $S$. The occurrence of P3 in $13 \%$ of the cases under Condition D indicate that it can sometimes occur in response to only one flash. However, it should be noted that only two of the eight Ss produced P3 under Condition D (see Table 3).

We might have expected to see a higher-amplitude VEP to Condition A than to Condition, $C$, as suggested by the findings of Bartlett \& White (1965), in which shorter ISIs were accompanied by greater-magnitude VEPs and subjective judgments of greater brightness. However, although a trend in this direction was seen (Table 2), it was not significant. The difference in our results and those of Bartlett \& White (1965) can be attributed to the widely divergent methodologies used in the experiments. Donchin et al (1963) reported that the VEPs for the first stimulus (test flash) were displaced by the VEPs of the second stimulus (blanking flash). In the present experiment our two stimuli were of equal intensity, and interference apparently occurred only when the two flashes were reported as "one" by Ss. Harter \& White (1967) used flash trains of $1-14$, with a constant ISI of $30 \mathrm{msec}$. They found that as Ss reported additional flashes, the number of components of the VEP increased correspondingly. Thus, the results of this experiment provide further evidence that ISI values and the number of stimuli presented affect VEPs, even for equally luminant pairs of light flashes.

$$
\text { REFERENCES }
$$

ANDREASSI, J. L., MAYZNER, M. S., BEYDA, D. R., \& DAVIDOVICS, $S$. Effects of induced muscle tension upon the visual evoked potential and motor potential. Psychonomic Science, 1970, 20, 245-247.

BARTLETT, N. R., \& WHITE, C. T. Evoked potentials and correlated brightness judgments of fused flash pairs as a function of inter-flash intervals. Science, 1965, 148, 980-981.

\section{Choice between reward magnitudes as a function of frequency of prior alternation between alternatives*}

\author{
MARGARET F. BURRILL † \\ Franklin and Marshall College, Lancaster, Pa. 17604
}

Independent groups of albino rats were administered 20 forced trials to each side of a T-maze before being permitted free choice between alternatives. Throughout training, runs to one side were followed by relatively large reward and runs to the other side by smaller reward. Tendency to run to larger reward on free trials was related to sequence in which forced trials had been administered, such that the more frequently Ss were forced to alternate runs to the two alternatives, the greater was their later tendency to select the alternative associated with larger reward.

In previously reported experiments (Burrill \& Spear, 1970), it has been found that the procedure of forcing frequent alternation of responses associated with different reward magnitudes may facilitate T-maze spatial or brightness discrimination in rats. Thus, Ss who were initially forced to one side (brightness) of the maze and large reward on odd-numbered trials and to the opposite side (brightness) and smaller reward on even-numbered trials later showed a stronger tendency to choose the more favorable alternative (MFA) than did groups that had received the same number of prior forced trials to the MFA and less favorable alternative (LFA) but with minimal alternations between stimuli, i.e., MFA and LFA forced trials were administered in unmixed blocks, all MFA trials preceding all LFA trials, or vice versa.

One possible explanation offered for these results was that frequent alternation of different reward magnitudes, by providing many comparisons of the two reward values in close temporal contiguity, might in some fashion increase Ss' tendency to attend to the variable of reward

* This research was supported by a Committee on Research grant from Franklin and Marshall College.

tRequests for reprints should be sent to Margaret F. Burrill, who is now at the Department of Psychology, State University College at Buffalo, $1300 \mathrm{Elmwood}$ Avenue, Buffalo, New York 14222. magnitude. In a series of $\mathrm{N}$ trials, half of which are forced to one alternative and half to another, the variable of number of alternations may take a number of different values. Only the extreme ends of the possible range were sampled in the Burrill and Spear study. The present experiment was designed as an extension of the previous work to include intermediate variable.

\section{SUBJECTS}

The Ss were 40 naive female albino rats, bred in the laboratories of Franklin and Marshall College. They were first-generation offspring of rats purchased from the Sprague-Dawley Co. in Madison, Wisconsin, and were about 65 days of age at the start of training.

The apparatus consisted of a $4 \mathrm{x} 4 \mathrm{ft}$ wooden cross maze. The walls and floor of the maze were painted flat gray. The hinged ceiling was of clear Plexiglas. For the purposes of this experiment, the arm directly opposite the startbox was blocked at the choice point by a clear Plexiglas guillotine door. Other guillotine doors were located $1 \mathrm{ft}$ from the ends of each arm (to delineate the start- and goalboxes) and at the entrance to each arm. The latter were employed for forcing purposes and to prevent retracing. Wooden baffles, 2 in. wide, were located $8 \mathrm{in}$. from the end of each goalbox such that the pellet values of the frequency-of-alternation 